\title{
Effect of the $[\mathrm{U}(\mathrm{IV})] /[\mathrm{U}(\mathrm{III})]$ ratio on selective chromium corrosion and tellurium intergranular cracking of Hastelloy $\mathrm{N}$ alloy in the fuel LiF- $\mathrm{BeF}_{2}-\mathrm{UF}_{4}$ salt
}

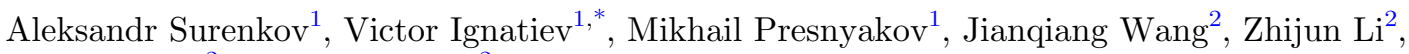 \\ Xinmei Yang ${ }^{2}$, and Zhimin Dai ${ }^{2}$ \\ 1 National Research Centre "Kurchatov Institute" (NRC KI), Kurchatov sq., 1, 123182 Moscow, Russia \\ 2 Shanghai Institute of Applied Physics (SINAP), Chinese Academy of Sciences, 201800 Shanghai, Jiading, P.R. China
}

Received: 29 January 2019 / Received in final form: 13 September 2019 / Accepted: 27 September 2019

\begin{abstract}
Effect of the $[\mathrm{U}(\mathrm{IV}) / \mathrm{U}(\mathrm{III})]$ ratio of fuel salt on selective chromium corrosion and tellurium intergranular cracking (IGC) of Hastelloy $\mathrm{N}$ alloy in the $\mathrm{LiF}-\mathrm{BeF}_{2}-\mathrm{UF}_{4}$ salt mixture was investigated. The chromium corrosion of Hastelloy $\mathrm{N}$ alloy is caused by the oxidation of chromium on the alloy surface by reaction with $\mathrm{UF}_{4}$. The tellurium IGC of Hastelloy $\mathrm{N}$ alloy is caused by the diffusion of tellurium along the grain boundaries with the formation of unstable tellurides with based metals and alloying additives. Results indicate that the selective chromium corrosion and the tellurium IGC of the Hastelloy $\mathrm{N}$ alloy in fuel salt can be controlled by the $[\mathrm{U}(\mathrm{IV})] /[\mathrm{U}(\mathrm{III})]$ ratio. The tellurium IGC of Hastelloy $\mathrm{N}$ alloy exposed in fuel $\mathrm{LiF}_{-} \mathrm{BeF}_{2}-\mathrm{UF}_{4}$ salt can be avoided. For temperatures up to $760{ }^{\circ} \mathrm{C}$ the selective chromium corrosion can be minimized to the acceptable level when the $[\mathrm{U}(\mathrm{IV})] /[\mathrm{U}(\mathrm{III})]$ ratio of fuel salt is bellow $30-40$.
\end{abstract}

\section{Introduction}

The advanced metallic material for molten salt reactor (MSR) primary circuit will operate at temperatures up to $700-750{ }^{\circ} \mathrm{C}[1-4]$. The internal surface of the reactor vessel will be exposed to salt-containing fissile, fertile, fission product materials, and would receive a maximum fast and thermal neutron fluences up to $10^{20}$ neutrons $/ \mathrm{cm}^{2}$ and $5 \times 10^{21}$ neutrons $/ \mathrm{cm}^{2}$, respectively [5]. The operating lifetime of a reactor will be up to $50 \mathrm{yr}$ with $80 \%$ load factor. Thus, the metal must have high corrosion resistance by the fuel salt.

An extremely large body of literature exists on the compatibility of metal alloys with molten salt fluoride mixtures for MSR primary and secondary circuits. Many of these works were done at US ORNL and involved either thermal or forced convection corrosion loops. These tests led to the development of high nickel INOR-8 (or Hastelloy $\mathrm{N}$ ) alloy for MSR. Hastelloy $\mathrm{N}$ has excellent chromium corrosion resistance to molten fluoride salts at temperatures considerably above those expected in MSR designs. Hastelloy $\mathrm{N}$ alloy was the sole structural material used in the $8 \mathrm{MWt}$ MSRE reactor at US ORNL and contributed significantly to the success of the experiment [2].

\footnotetext{
* e-mail: ignatievvictor@yandex.ru
}

Two main problems of Hastelloy $\mathrm{N}$ requiring further development turned up during the operation of the MSRE. The first was that the Hastelloy N used for the MSRE was subject of "radiation hardening" due to accumulation of helium at grain boundaries. The second problem came from the discovery of tiny cracks on the inside surface of the Hastelloy $\mathrm{N}$ piping for MSRE. It was found that these cracks with a depth of $100-250 \mu \mathrm{m}$ were caused by the fission product tellurium [2]. Later US ORNL [6-9] and NRC KI [10-13] showed that this tellurium attack could be controlled by keeping the fuel on the reducing side. This could be done by adjustment of the chemistry so that about $2 \%$ or more of the uranium is in the form of $\mathrm{UF}_{3}$, as opposed to $\mathrm{UF}_{4}$.

In US ORNL tests $[8,9]$ with the Hastelloy-N specimens it was assumed that in the case of a low $[\mathrm{U}(\mathrm{IV})] /[\mathrm{U}$ (III)] ratio, with sufficient amount of $\mathrm{UF}_{3}$ and essential chromium ions in the molten salt, then all the free tellurium would form an insoluble and stable chromium telluride by the following reaction:

$$
2 \mathrm{UF}_{3}+\mathrm{CrF}_{2}+\mathrm{Te}^{0} \rightarrow 2 \mathrm{UF}_{4}+\mathrm{CrTe} .
$$

Reaction (1) prevents the transfer of free tellurium to the structural metal and avoids the tellurium IGC of the Hastelloy- $\mathrm{N}$ alloy, but this also led to an increase of the $\mathrm{UF}_{4}$ concentration in the fuel salt. According to Mamantov's calculation $[8,9]$, the $[\mathrm{U}(\mathrm{IV})] /[\mathrm{U}(\mathrm{III})]$ ratio of about 150 


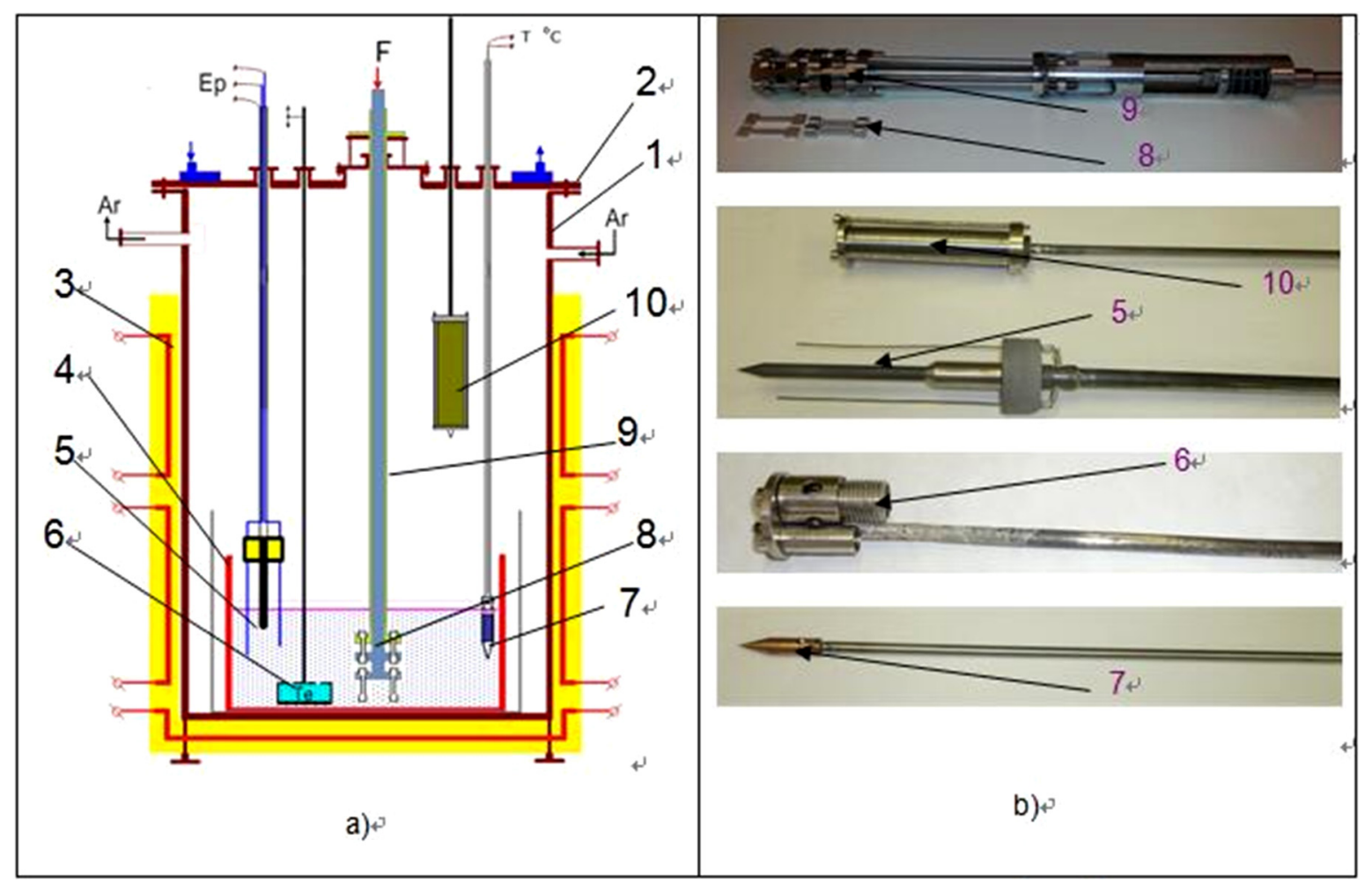

Fig. 1. Corrosion facility layout (a) and its main components (b): 1 - high temperature furnace, 2 - furnace cover, 3 - electric heaters, 4 - NP2 nickel vessel, 5 - device for measuring redox potential, 6 - container for tellurium metal or nickel difluoride, 7 - sampler and thermocouple, 8 - alloy specimens, 9 - stick providing mechanical load on metallic specimens, 10 - beryllium reducer.

should be a critical value for the formation of $\mathrm{CrTe}$ compound in molten $71.7 \mathrm{LiF}-16.0 \mathrm{BeF}_{2}-12.0 \mathrm{ThF}_{4}-0.3 \mathrm{UF}_{4}$ salt mixture at $650{ }^{\circ} \mathrm{C}$. In ORNL experiments with Hastelloy-N alloy $[8,9]$ was found no Te IGC traces for $[\mathrm{U}(\mathrm{IV})] /[\mathrm{U}(\mathrm{III})]$ ratios below 80 .

In this paper for the molten $\mathrm{LiF}-\mathrm{BeF}_{2}-\mathrm{UF}_{4}$ salt mixture, we studied effect of $[\mathrm{U}(\mathrm{IV})] /[\mathrm{U}(\mathrm{III})]$ ratio in the range of 30-90 on the selective chromium corrosion and the tellurium IGC of the Hastelloy $\mathrm{N}$ alloy at temperatures up to $800{ }^{\circ} \mathrm{C}$.

\section{Experimental}

\subsection{The corrosion facility}

The corrosion facility as shown in Figure 1 consists of a furnace 1 made of $316 \mathrm{SS}$ with an inner diameter of $145 \mathrm{~mm}$ and a height of $450 \mathrm{~mm}$, sealed from above by a flange cover 2 , equipped externally by three heaters 3 . Test section 4 made of nickel metal has inner diameter/height of $140 \mathrm{~mm} / 180 \mathrm{~mm}$ with molten salt volume of about $1.5 \mathrm{~L}$. Inside the furnace, a vacuum or argon atmosphere can be maintained. To measure the redox potential of the molten salt, device 5 is used. To change the $[\mathrm{U}(\mathrm{IV})] /[\mathrm{U}(\mathrm{III})]$ ratio, batcher 6 with, respectively, $\mathrm{NiF}_{2}$ oxidizer or granulated metallic Te was used. It was equipped by motor to ensure the mixing of fuel salt for delivery of tellurium to the metallic specimen surface. Measurement of the temperature is carried out by thermocouple 7 coupled with the fuel salt sampler for chemical analysis during corrosion test. The assembly 8 with metallic specimens is inserted in the test section with molten salt through the sealing valve. Alloy specimens joined into two strips (without and under a mechanical load of $20 \mathrm{MPa}$ ) are placed at the height of the molten salt pool and flushed by the upstream flow of the fuel salt. In order to purify the fuel salt from impurities and to decrease the $[\mathrm{U}(\mathrm{IV})] /[\mathrm{U}(\mathrm{III})]$ ratio, the metallic beryllium was used as reducer 10. All elements in contact with the molten salt are made of NP2 nickel (Ni-99.5, $\mathrm{Fe}-\leq 0.1, \mathrm{Si}-\leq 0.15, \mathrm{Mg}-\leq 0.1, \mathrm{Cu}-\leq 0.1, \mathrm{Mn}-\leq 0.05$, $\mathrm{C}-\leq 0.1$, others $-\leq 0.01$ in wt.\%) or Monel alloy $(\mathrm{Ni}$ $+\mathrm{Co}$-base, $\mathrm{Cu}-27.0-29.0, \mathrm{Fe}-2.0-3.0, \mathrm{Mn}-1.2-1.8$, $\mathrm{Mg}-0.1, \mathrm{Si}-0.05, \mathrm{C}-0.2$, others $-\leq 0.01$ in wt.\%).

\subsection{The preparation of the fuel salt}

In general, the purification procedure for the fuel $71 \mathrm{LiF}-$ $27 \mathrm{BeF}_{2}-2 \mathrm{UF}_{4}$ (mole \%) salt mixture included three stages.

In our experiments we used anhydrous lithium fluoride, beryllium difluoride, and uranium tetrafluoride metal fluorides with a content of the main product up to 99.95 wt. \%.

At first stage to remove oxides and water, individual metal fluoride powder was mixed with ammonium hydrogen fluoride at a molar ratio of about 1:1 and heated gradually to $400-450{ }^{\circ} \mathrm{C}$ within $24 \mathrm{~h}$ in a copper crucible, and argon was purged above the salt powder surface in the corrosion facility (see Fig. 1). 
Table 1. The $[\mathrm{U}(\mathrm{IV})] /[\mathrm{U}(\mathrm{III})]$ ratio and metal impurities (wt.\%) content in the fuel $71.2 \mathrm{LiF}-26.8 \mathrm{BeF}_{2}-2 \mathrm{UF}_{4}$ salt mixture before and after corrosion tests.

\begin{tabular}{lllllll}
\hline Fuel salt & $\begin{array}{l}{[\mathrm{U}(\mathrm{IV})] /} \\
{[\mathrm{U}(\mathrm{III})]}\end{array}$ & $\mathrm{Ni}$ & $\mathrm{Cr}$ & $\mathrm{Fe}$ & $\mathrm{Cu}$ & $\mathrm{Te}$ \\
\hline $\begin{array}{l}\text { After melting and } 4 \mathrm{~h} \text { exposure at } T=700^{\circ} \mathrm{C} \\
\text { before beryllium treatment }\end{array}$ & $1.7 \times 10^{5}$ & 0.046 & 0.018 & 0.054 & 0.012 & - \\
$\begin{array}{l}\text { After double beryllium treatment } \\
\text { and } 2 \mathrm{~h} \text { exposure at } T=700{ }^{\circ} \mathrm{C}\end{array}$ & 200 & 0.002 & 0.021 & 0.011 & 0.015 & - \\
$\begin{array}{l}\text { After } 256 \mathrm{~h} \text { specimens exposure in the corrosion test } 1 \\
\text { at } T=700-720^{\circ} \mathrm{C} \text { and adding } 5 \mathrm{~g} \text { of Te metal }\end{array}$ & 35 & 0.006 & 0.0026 & 0.019 & 0.0039 & 0.0029 \\
$\begin{array}{l}\text { for the first time } \\
\text { After } 248 \mathrm{~h} \text { specimens exposure in corrosion test } 2\end{array}$ & & & & & & \\
$\begin{array}{l}\text { at } T=760-800^{\circ} \mathrm{C} \text { and adding } 1.63 \mathrm{~g} \text { of } \mathrm{NiF}_{2} \text { and } 5 \mathrm{~g} \\
\text { of } \mathrm{Te} \text { metal for the second time }\end{array}$ & & 0.029 & 0.0043 & 0.0051 & 0.006 & 0.02 \\
\hline
\end{tabular}

- Elements are not added and detected.

At the second stage, the prepared $2250 \mathrm{~g}$ of $72.6 \mathrm{LiF}-$ $27.4 \mathrm{BeF}_{2}$ salt mixture (mole $\%$ ) of powders was vacuumed at $450^{\circ} \mathrm{C}$, while controlling the pressure of the exhaust gases. After it was melted in a nickel crucible, heated up to $750^{\circ} \mathrm{C}$ in "very pure" argon atmosphere and kept at this temperature for some hours. Later $450 \mathrm{~g}$ of uranium tetrafluoride powder was added to the melt surface through an inlet valve after its cooling. The mixture was melted again in an argon atmosphere at $700^{\circ} \mathrm{C}$ within $4 \mathrm{~h}$ until the $\mathrm{UF}_{4}$ is completely melted and the fuel salt is homogenized. Finally, the required fuel $71.2 \mathrm{LiF}-$ $26.8 \mathrm{BeF}_{2}-\mathrm{UF}_{4}$ (mole \%) salt mixture was obtained. As can be seen from Table 1, the prepared fuel $71.2 \mathrm{LiF}$ $26.8 \mathrm{BeF}_{2}-2 \mathrm{UF}_{4}$ salt mixture (mole \%) has impurity content (in wt.\%) of nickel - 0.046, iron - 0.054, and chromium -0.018 . The source of these metal impurities is derived from excess hydrogen fluoride, which was adsorbed in small quantities on individual fluoride powders during treatment by ammonium hydrofluoride. Hydrogen fluorine reacts with the material of the NP-2 crucible, which results in the accumulation of nickel and iron fluorides in molten salt. These impurities determine the redox potential of molten salt and ultimately affect the corrosion process in the "fuel salt-structural metal" system.

At the third stage, the removal of metal fluoride impurities was achieved by the treatment of molten $71.2 \mathrm{LiF}-26.8 \mathrm{BeF}_{2}-2 \mathrm{UF}_{4}$ salt mixture (in mole \%) with metallic beryllium at $700^{\circ} \mathrm{C}$.

\subsection{The determination of $[\mathrm{U}(\mathrm{IV})] /[\mathrm{U}(\mathrm{III})]$ ratio}

The $[\mathrm{U}(\mathrm{IV})] /[\mathrm{U}(\mathrm{III})]$ ratio of fuel salt was determined by voltammetric measurements of peak potentials, when oneelectron process of the uranium ions recharging $\mathrm{U}^{+4}+\mathrm{e} \leftrightarrow$ $\mathrm{U}^{+3}$ occurs [13-17]. The registration of cyclic voltammogram $(\mathrm{CV})$ was performed in a three-electrode mode of polarization in different ranges of the reversal potential in positive and negative region. In the negative region it reached capacity for the remediation of uranium metal by the reaction $\mathrm{U}^{+3}+3 \mathrm{e} \leftrightarrow \mathrm{U}^{0}$. Three electrode device for measuring redox potential used for the continuous monitoring of the $[\mathrm{U}(\mathrm{IV})] /[\mathrm{U}(\mathrm{III})]$ ratio is shown in Figure 1b. The molybdenum wire was used as both working and reference electrodes; auxiliary electrode was made of reactor-grade graphite.

The $[\mathrm{U}(\mathrm{IV})] /[\mathrm{U}(\mathrm{III})]$ ratio was determined by the following equation (CVs of fuel salt recorded in the range of potentials for the uranium recharge were used, Fig. 2a):

$$
[\mathrm{U}(\mathrm{IV})] /[\mathrm{U}(\mathrm{III})]=\exp \left[-\left(E_{0.855 p}\right) *(\mathrm{RT} / \mathrm{F})\right],
$$

where $E_{0.855 p}$ is a potential of the point on cathodic voltammogram at $I=0.855 \times I_{\mathrm{p}}$; it is approximately equal to potential of polarographical half-wave and thermodynamic formal (standard) redox potential of U[(IV)]/ $[\mathrm{U}(\mathrm{III})]$ couple. The $\mathrm{U}[(\mathrm{IV})] /[\mathrm{U}(\mathrm{III})]$ ratio can be changed by the addition of beryllium metal or nickel difluoride to the fuel salt. $\mathrm{U}[(\mathrm{IV})] /[\mathrm{U}(\mathrm{III})]$ ratio and the corrosion impurities content in fuel $71.2 \mathrm{LiF}-26.8 \mathrm{BeF}_{2}-2 \mathrm{UF}_{4}$ salt mixture before and after tests are shown in Figure 2 and Table 1, respectively.

\subsection{Specimens before and after exposure in the fuel salt}

The alloy selected for corrosion studies is the Hastelloy N alloy (UNS10003) produced by US Haynes Corporation. A preliminary material study has been carried out with the alloys specimens in the state of supply, including chemical, metallographic, and metallographic analysis, as well as measurement of mechanical properties. The metals content in the alloys was determined by means of plasma emission spectrometry (see Tab. 2). The mechanical properties of alloy were tested by unidirectional center tensile test. The test was carried out on the Zwick/Roell comprehensive test machine at a temperature of $23^{\circ} \mathrm{C}$. The strength index $\sigma_{\mathrm{B}}-$ ultimate strength, $\sigma_{02}-$ yield strength and $\delta-$ relative elongation of the tested alloys are given in Table 3 . The metallographic structure US Hastelloy- $\mathrm{N}$ alloy before and after tests are shown in Figures 3-6. 


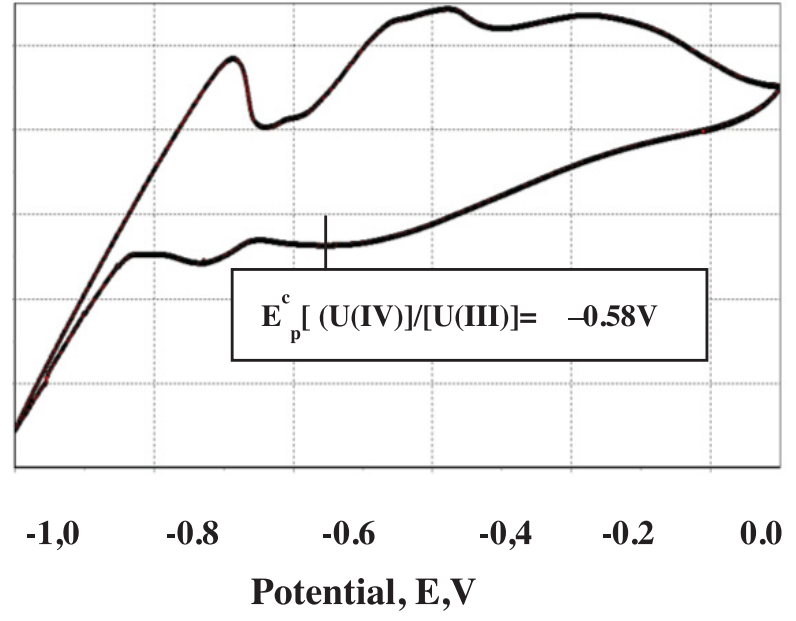

a)

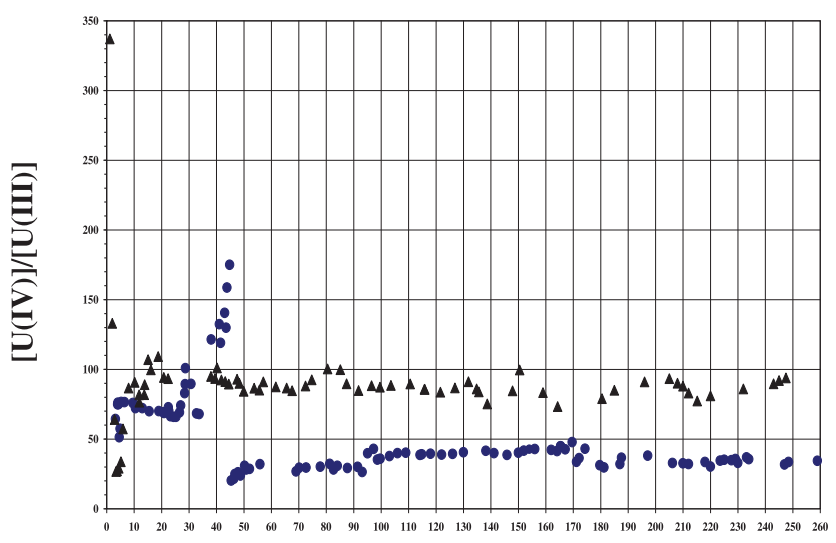

\section{Exposure time, hr}

b)

Fig. 2. $\mathrm{CV}$ of the fuel salt at $T=700{ }^{\circ} \mathrm{C}$ after its purification before the corrosion test (a) and the $[\mathrm{U}(\mathrm{IV})] /[\mathrm{U}$ (III)] ratio vs. exposure time (b) for: $\bullet$ first and $\boldsymbol{\Lambda}$ second tests [13].

Table 2. Chemical composition of Hastelloy N alloy specimens (UNS\#10003) (in wt.\%).

\begin{tabular}{|c|c|c|c|c|c|c|c|c|c|c|c|c|}
\hline $\mathrm{Ni}$ & $\mathrm{Cr}$ & Mo & $\mathrm{Al}$ & $\mathrm{Ti}$ & $\mathrm{Fe}$ & Mn & $\mathrm{Nb}$ & $\mathrm{Si}$ & $\mathrm{W}$ & $\mathrm{Co}$ & $\mathrm{V}$ & $\mathrm{C}$ \\
\hline Base & 7.2 & 16.2 & 0.23 & $<0.005$ & 3.3 & 0.50 & $<0.009$ & 0.30 & $<0.005$ & 0.027 & $<0.03$ & 0.06 \\
\hline
\end{tabular}

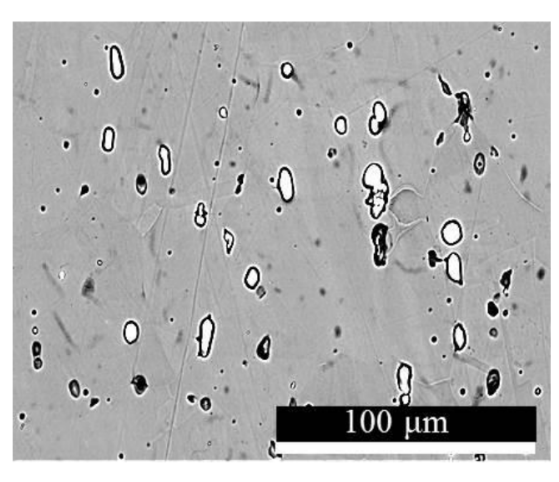

a)

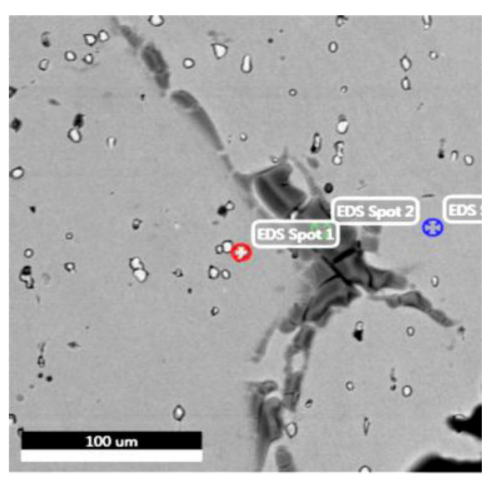

b)

$\begin{array}{ccc}\text { Sample } & 1 & 3 \\ \mathrm{C} & 8,20 & 3,30 \\ \mathrm{~A} 1 & 0,21 & 0,35 \\ \mathrm{Si} & 2,17 & 0,32 \\ \mathrm{Mo} & 51,53 & 11,57 \\ \mathrm{Cr} & 5,76 & 6,98 \\ \mathrm{Mn} & 0,31 & 0,67 \\ \mathrm{Fe} & 1,57 & 4.14 \\ \mathrm{Ni} & 30,13 & 72.52\end{array}$

c)

Fig. 3. Metallographic structure of the Hastelloy-N alloy before exposure: (a) the center of the specimen surface; (b) the cross section of several grains; (c) composition of the grains and the particulate inclusions (in mass \%).

Table 3. Strength properties of Hastelloy-N alloy.

\begin{tabular}{llll}
\hline Alloy & $\sigma_{\mathrm{B}}, \mathrm{MPa}$ & $\sigma_{02}, \mathrm{MPa}$ & $\delta, \%$ \\
\hline Hastelloy-N & $810 \pm 10$ & $370 \pm 10$ & $42 \pm 2$ \\
\hline
\end{tabular}

The molybdenum and silicon content in the Hastelloy$\mathrm{N}$ alloy is very high (see Tab. 2). The high content of these elements will form coarsely dispersed carbides in the grain and grain boundary. This conclusion is proved by metallographic data obtained by electron scanning microscope. Figures 3 and 4 show the metallographic structure of the alloy far away from reaction surface before and after exposure at $800{ }^{\circ} \mathrm{C}$. As can be seen, large-size circular particles $(5-10 \mu \mathrm{m})$ are mainly concentrated on the boundaries of the grains. According to the result of micro-spectrum analysis, these particles are mainly composed of Mo, Mn and Si carbides. In our tests after annealing, at the phase boundaries additional inclusion chains appear that are observed in all micrographs of the structure of alloy specimens. Comparison of the particle size before and after exposure shows a slight increase in the size of these particles. This allows us to conclude 

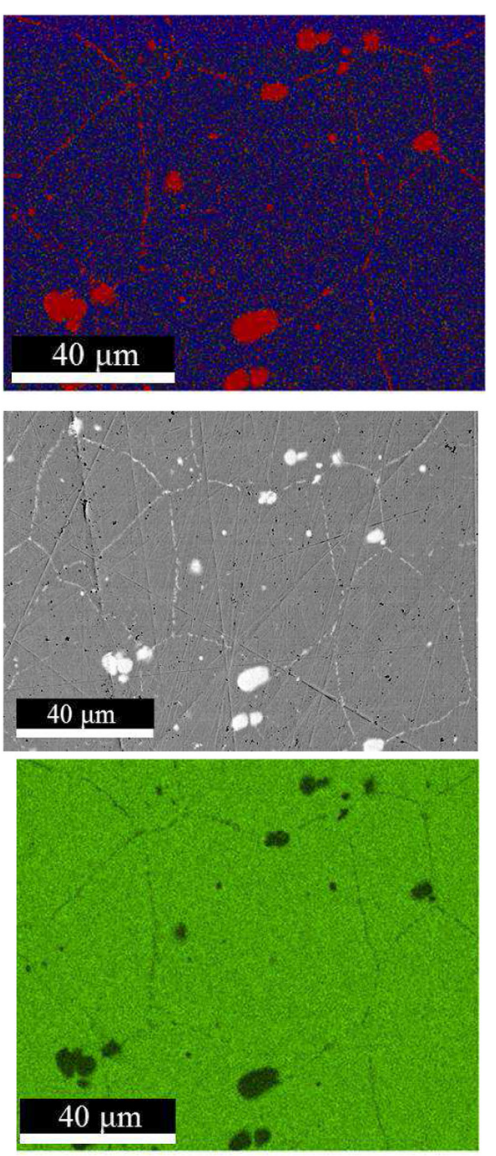

Ni K

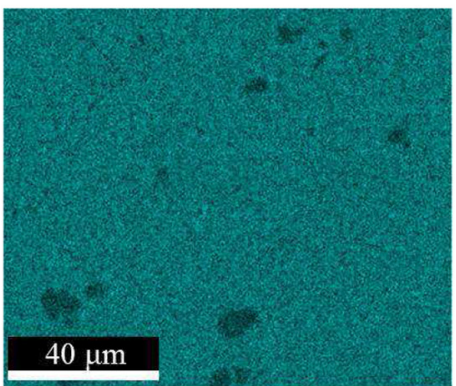

Fe K

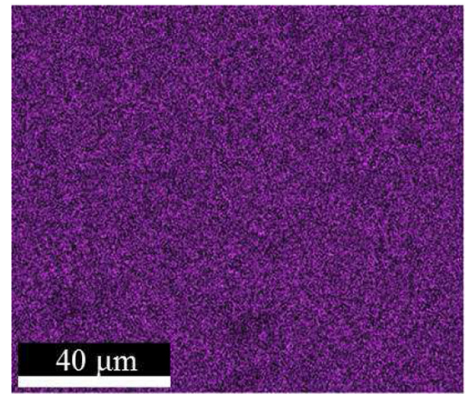

Mn K

\begin{tabular}{ccccc} 
Element & \multicolumn{3}{c}{ Concentration on the specimen surface, wt.\% } \\
$\mathrm{C}$ & 4.98 & 4.93 & 3.87 & 6.28 \\
$\mathrm{Al}$ & 1.00 & 1.27 & 0.85 & 0.00 \\
$\mathrm{Si}$ & 1.25 & 0.76 & 0.51 & 0.13 \\
$\mathrm{Mo}$ & 13.23 & 10.26 & 11.00 & 19.22 \\
$\mathrm{Cr}$ & 8.67 & 6.49 & 5.54 & 5.72 \\
$\mathrm{Mn}$ & 0.81 & 1.03 & 0.64 & 0.00 \\
$\mathrm{Fe}$ & 4.85 & 4.37 & 3.28 & 2.86 \\
$\mathrm{Ni}$ & 62.78 & 66.92 & 69.96 & 65.78 \\
$\mathrm{Cu}$ & 2.14 & 3.86 & 4.19 & 0.01
\end{tabular}

Proportion of the selected element phase on the reaction surface:

Phase

Contents, wt. \%

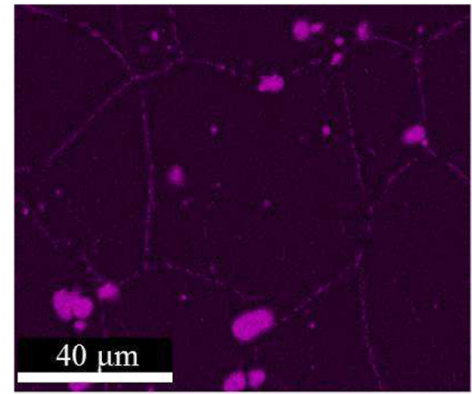

Mo L

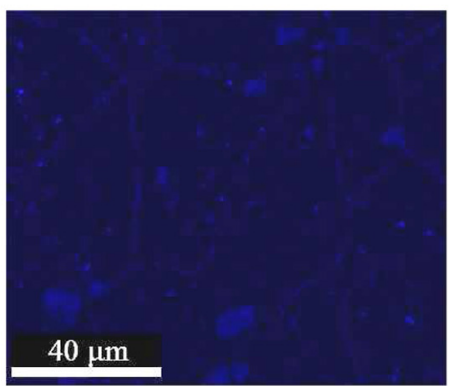

Si K

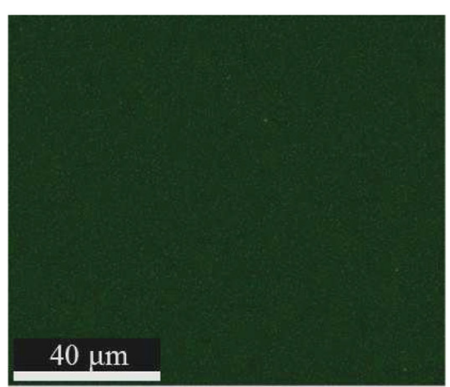

A1 K
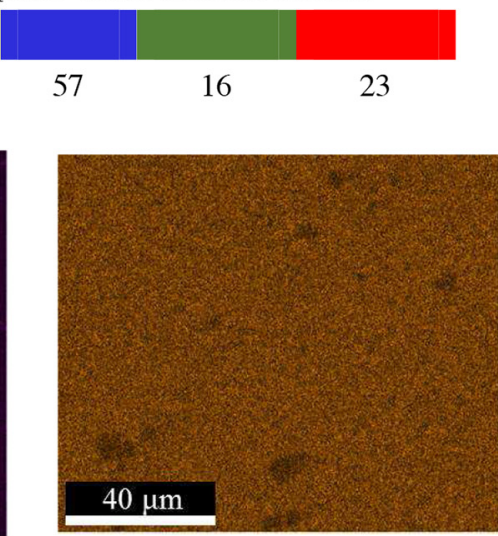

Cr K

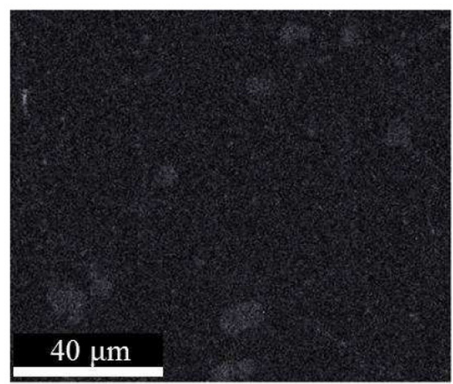

C K

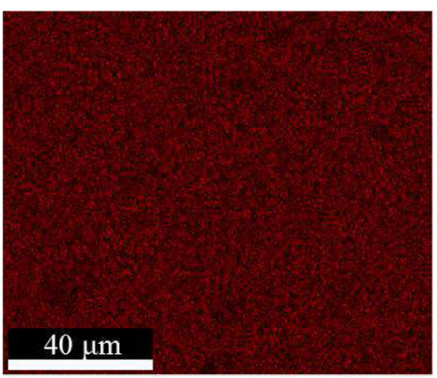

$\mathrm{Cu} \mathrm{K}$

Fig. 4. MPCA metallographic structure and element composition data for different surface areas of the Hastelloy-N alloy after annealing at $800^{\circ} \mathrm{C}$. 

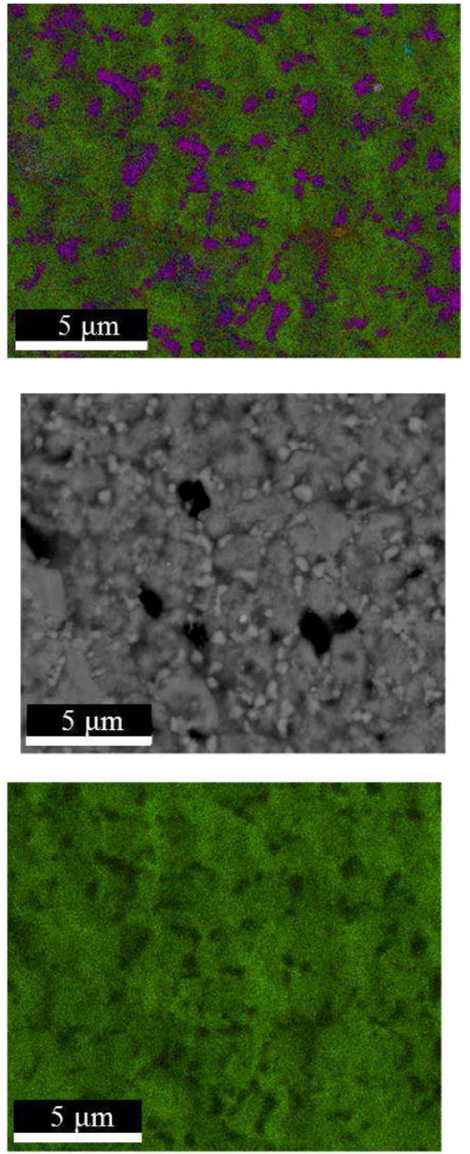

Ni K

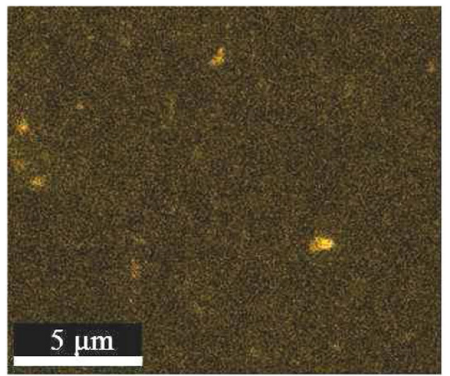

Te K

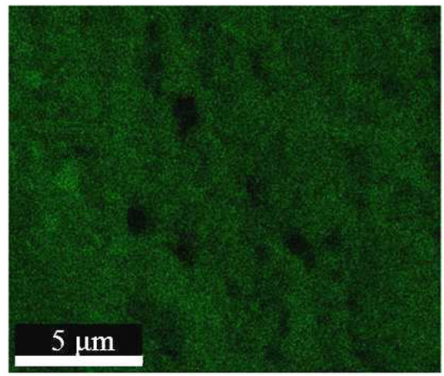

Al K

\begin{tabular}{ccccccccc}
\multirow{2}{*}{ Element } & \multicolumn{7}{l}{ Concentration on the specimen surface, wt.\% } \\
\cline { 2 - 6 } $\mathrm{C}$ & 17,23 & 14,85 & 11,85 & 15,55 & 14,36 & 16,64 & 9,62 \\
$\mathrm{Al}$ & 0,00 & 0,23 & 0,28 & 0,37 & 0,11 & 1,28 & 0,06 \\
$\mathrm{Si}$ & 2,34 & 1,04 & 0,80 & 2,67 & 1,52 & 0,77 & 0,69 \\
$\mathrm{Mo}$ & 26,33 & 10,17 & 6,33 & 8,25 & 16,91 & 5,21 & 5,12 \\
$\mathrm{Te}$ & 0,04 & 0,74 & 0,63 & 1,00 & 0,33 & 2,16 & 0,26 \\
$\mathrm{Cr}$ & 2,78 & 6,39 & 4,25 & 3,59 & 3,01 & 3,04 & 2,49 \\
$\mathrm{Mn}$ & 0,00 & 0,44 & 0,69 & 0,73 & 0,09 & 0,63 & 0,13 \\
$\mathrm{Fe}$ & 2,15 & 5,24 & 4,80 & 4,47 & 3,56 & 8,02 & 3,53 \\
$\mathrm{Ni}$ & 46,96 & 56,19 & 64,78 & 57,49 & 56,76 & 57,27 & 74,82 \\
$\mathrm{Cu}$ & 2.17 & 4.72 & 5.58 & 5.08 & 3.37 & 4.98 & 3.28
\end{tabular}

Proportion of the selected element phase on the reaction surface:

\begin{tabular}{l|lllllll|l|l|} 
Phase & & & & & & & & \\
Contents, in wt. \% & 2 & 8 & 24 & 22 & 11 & 6 & 23
\end{tabular}

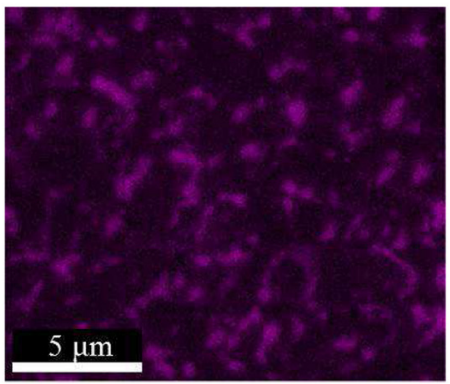

Mo K

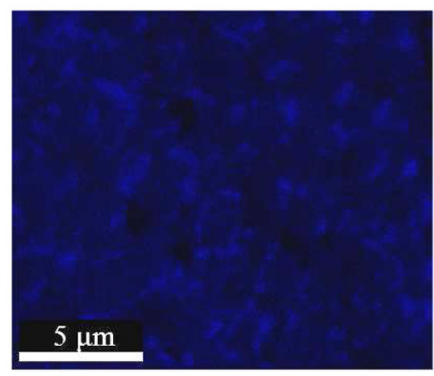

Si K

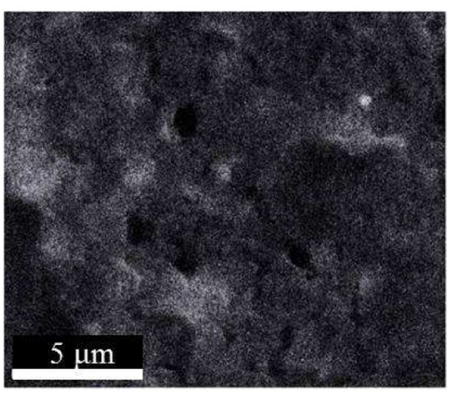

C K

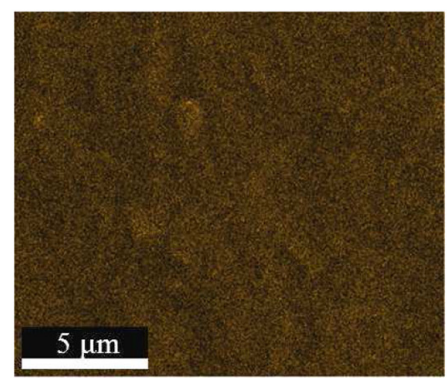

Cr K

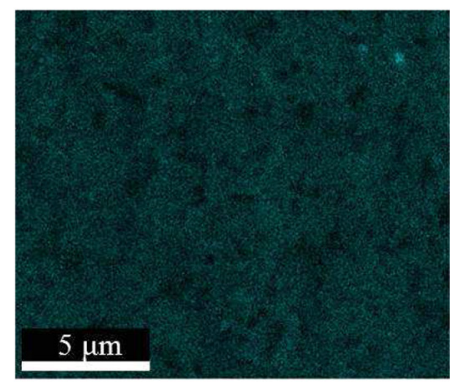

$\mathrm{Fe} \mathrm{K}$

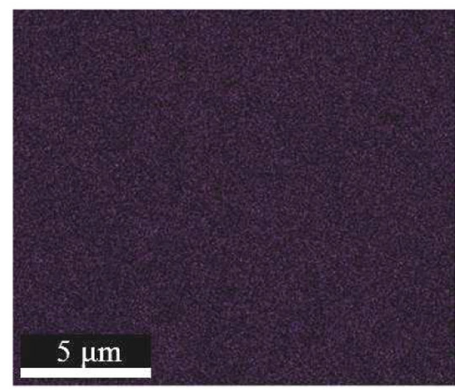

$\mathrm{Mn} \mathrm{K}$

Fig. 5. MPCA metallographic structure and element composition data for different surface areas of the Hastelloy-N alloy after exposure in the fuel $71 \mathrm{LiF}-27 \mathrm{BeF}_{2}-2 \mathrm{UF}_{4}$ salt with $[\mathrm{U}(\mathrm{IV})] /[\mathrm{U}(\mathrm{III})]$ ratio 42 at $760{ }^{\circ} \mathrm{C}$ : phases of the alloy reaction surface and element content in the major phases. 

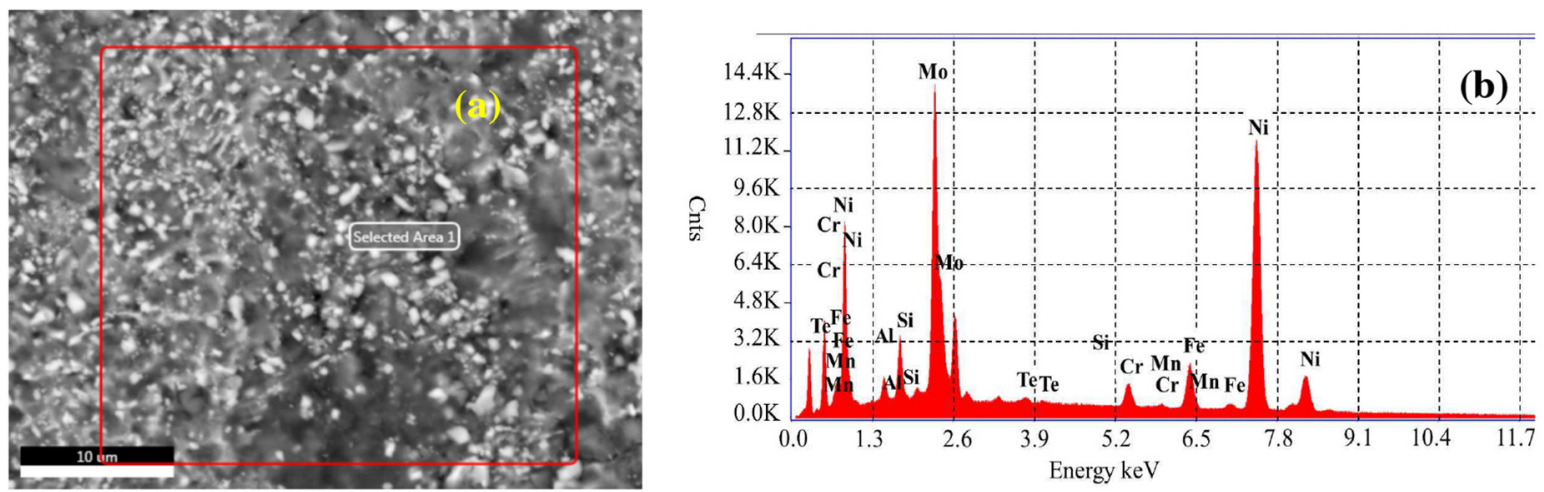

Concentration on the specimen surface, wt.\%

(c)

\begin{tabular}{|c|c|c|c|c|c|c|c|c|}
\hline $\mathrm{Ni}$ & $\mathrm{Mo}$ & $\mathrm{Cr}$ & $\mathrm{Fe}$ & $\mathrm{Al}$ & $\mathrm{Si}$ & $\mathrm{Mn}$ & $\mathrm{Te}$ & $\mathrm{C}$ \\
\hline 42.06 & 25.83 & 1.99 & 4.01 & 0.79 & 2.53 & 0.30 & 1.11 & 21.38 \\
\hline
\end{tabular}
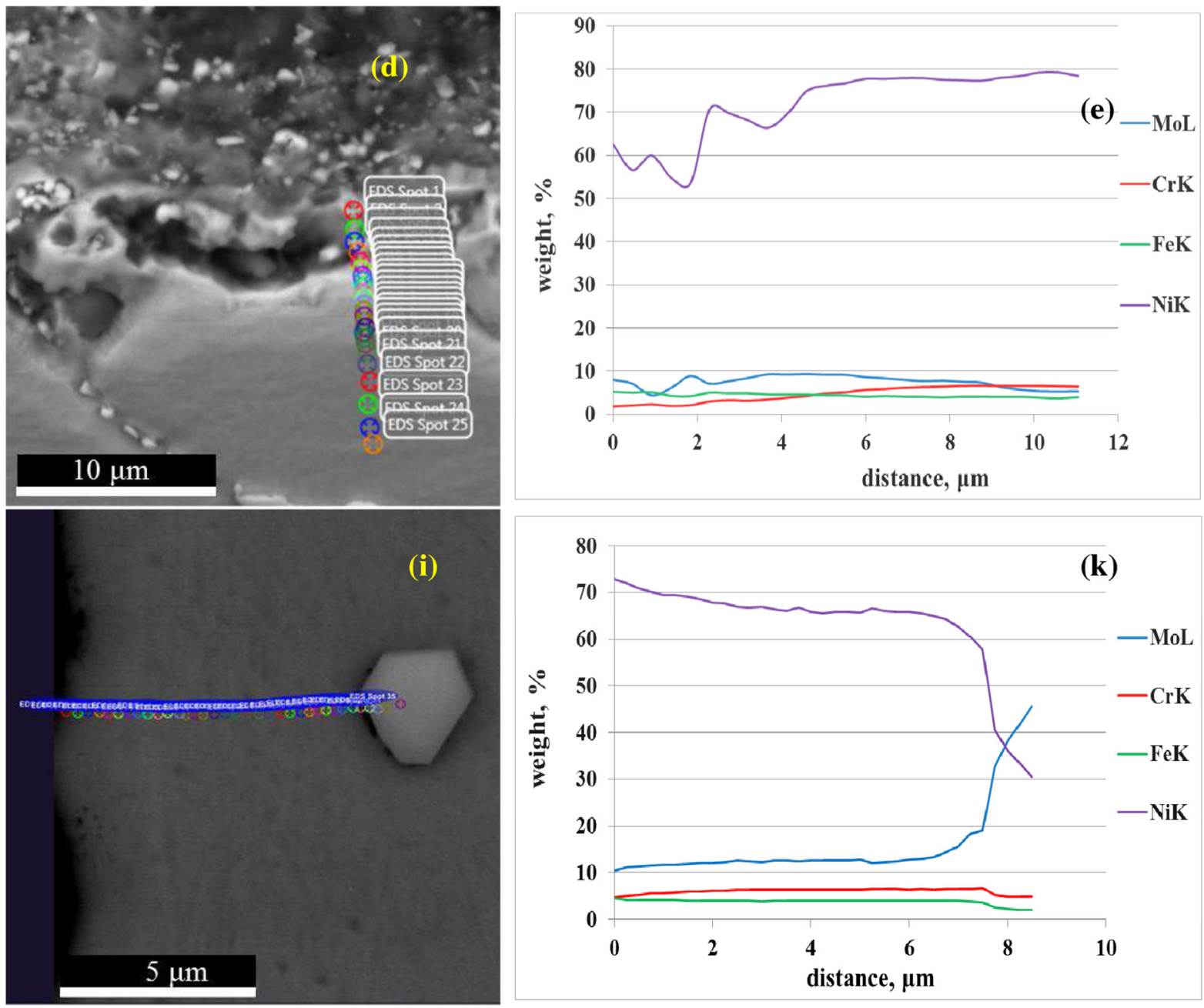

Fig. 6. Scanning data (scanning line and element composition) on allocated area from surface to grain depth of the Hastelloy-N alloy: (a)-(d) after exposure at $T=800^{\circ} \mathrm{C}$ with $[\mathrm{U}(\mathrm{IV})] /[\mathrm{U}(\mathrm{III})]$ ratio $=85$, (i) and (k) after exposure at $T=760^{\circ} \mathrm{C}$ with $[\mathrm{U}(\mathrm{IV})] /$ $[\mathrm{U}(\mathrm{III})]=42$. 

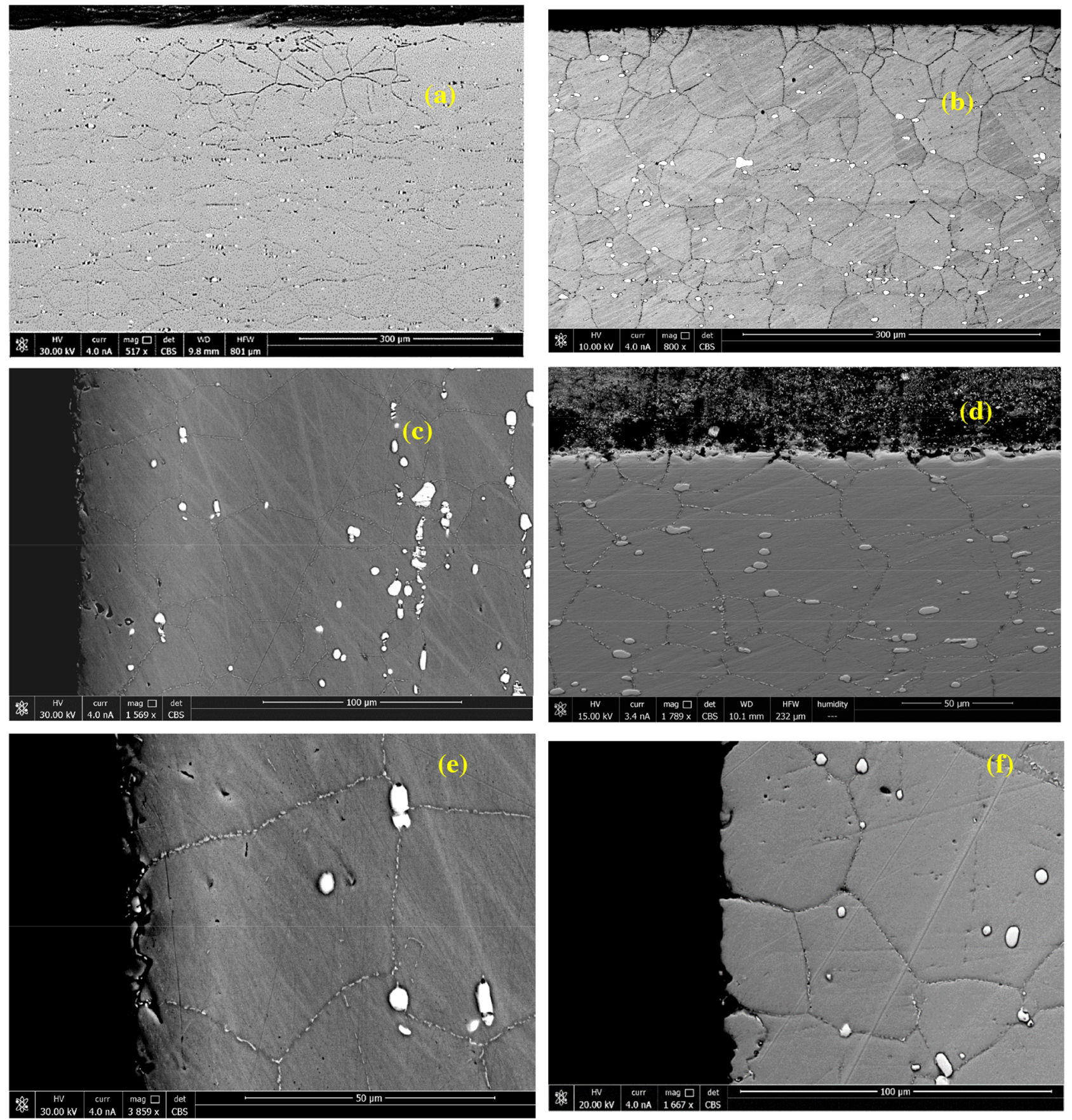

Fig. 7. SEM images of metallographic structure of the undersurface layer for the Hastelloy-N after exposure in fuel $71.2 \mathrm{LiF}-26.8 \mathrm{BeF} 2^{-}$ $2 \mathrm{UF}_{4}$ salt containing tellurium: (a), (c), (e) after exposure with $[\mathrm{U}(\mathrm{IV})] /[\mathrm{U}(\mathrm{III})]$ ratio 42 at $T=760{ }^{\circ} \mathrm{C}$ (left), (b), (d), (f) after exposure with $[\mathrm{U}(\mathrm{IV})] /[\mathrm{U}(\mathrm{III})]$ ratio 85 at $T=800^{\circ} \mathrm{C}$ (right).

that the alloy structure is thermally unstable and that during the high-temperature annealing, secondary carbide phases of molybdenum with nickel and silicon are formed and enlarged mainly at the grain boundaries at the nodes. After annealing, carbide particles are clearly visible at the scanning sites located both near and far from the specimen's surface in contact with the fuel salt (see Figs. 7, 8). The elemental composition of these particles shows a significantly increased content of molybdenum, silicon and carbon.

After exposure in the fuel salt, alloy specimens were washed during $60 \mathrm{~h}$ in $5 \%$ aluminum nitrate solution, and then weighed. To open surface cracks and perform subsequent metallographic analysis, all specimens were stretched to break. The sections of the prepared specimens near break area were studied by optical 

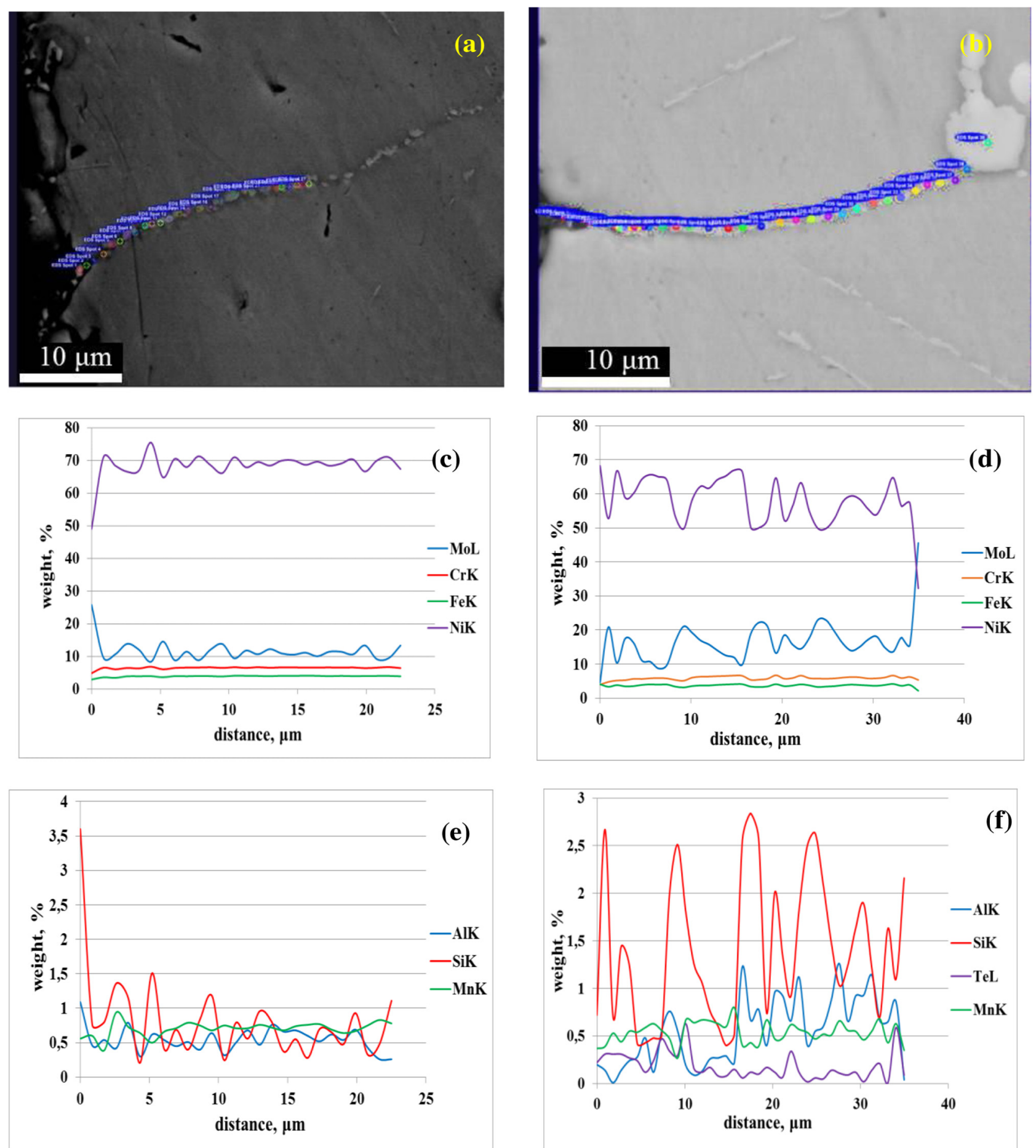

Fig. 8. Scanning data for the under surface of the Hastelloy-N along the grain boundary exposed in the fuel salt, (a), (c), (e) scan line, the concentration of the main metal and alloying additives in the specimen, after test with $[\mathrm{U}(\mathrm{IV})] /[\mathrm{U}(\mathrm{III})] \mathrm{ratio} 42$ at $T=760^{\circ} \mathrm{C}(\mathrm{left})$, (b), (d), (f) scan line, the concentration of the main metal and alloy additive in the specimen, after test with $[\mathrm{U}(\mathrm{IV})] /[\mathrm{U}(\mathrm{III})]$ ratio 85 at $T=800^{\circ} \mathrm{C}$ (right).

microscope to determine whether there are surface cracks, membranes, holes, or other traces deals with corrosion attack. The resistance of the alloy to tellurium grain boundary corrosion cracking can be evaluated by measuring the average depth and maximum depth of cracks in the alloy and calculating the parameter $K$ that reflects the corrosion degree of grain boundary in the alloy (the number of cracks on the sample surface along the tensile line $1 \mathrm{~cm}$ multiplied by the average depth in micrometers). The rate of uniform corrosion was determined by measuring the weight loss of three specimens during the exposure time in each test. 


\subsection{Analysis}

Tellurium inclusions on the surface, inside grain boundaries and on the grain body of specimens were carried out by means of Helios NanoLab 600 (FEI, USA) electron microscopy with field electron emission at a maximum acceleration voltage of $30 \mathrm{kV}$. In order to avoid oxidation of specimen slices by the laboratory atmosphere and remove organic impurities, the surface of the specimen slice was preliminary cleaned by argon plasma with Plasma Cleaner (Fischione, USA) equipment.

An auxiliary device of Phoenix solid-state detector (US EDAX inc.) with a resolution of $\leq 138 \mathrm{eV}$ was used to measure the roentgen spectral parameters of the specimen in various regions. Meanwhile, the effective size of the target material is about $20 \mathrm{~nm}$ in diameter and $35-40 \mathrm{~nm}$ in depth. To obtain the EMF spectrums, an acceleration voltage of $8 \mathrm{kV}$ was used. The diffusion activity of tellurium along the grain boundary and contents of the tellurium inclusions on the surface of the specimen were determined by energy dispersive X-ray microanalysis.

\section{Results and discussion}

Nickel difluoride was added to the fuel salt to change the $[\mathrm{U}(\mathrm{IV})] /[\mathrm{U}(\mathrm{III})]$ ratio before the second test. After the addition of $\mathrm{NiF}_{2}$ in the fuel salt, uranium trifluoride was oxidized to the uranium tetrafluoride by the following reaction:

$$
2 \mathrm{UF}_{3}+\mathrm{NiF}_{2} \rightarrow 2 \mathrm{UF}_{4}+\mathrm{Ni}
$$

As a result, the $[\mathrm{U}(\mathrm{IV})] /[\mathrm{U}(\mathrm{III})]$ ratio increased up to 500. After the tellurium metal addition and insertion of the alloy specimens to the fuel salt, the $[\mathrm{U}(\mathrm{IV})] /[\mathrm{U}(\mathrm{III})]$ ratio dropped down from 330 to 30 in the first $5 \mathrm{~h}$ of exposure, later after $48 \mathrm{~h}$ of exposure the $[\mathrm{U}(\mathrm{IV})] /[\mathrm{U}(\mathrm{III})]$ ratio stabilized at $90 \pm 10$. This is due to the reduction of uranium tetrafluoride to uranium trifluoride by chromium from the alloy specimens under test according to the reaction:

$$
2 \mathrm{UF}_{4}(\mathrm{~m})+\mathrm{Cr}(\mathrm{ss}) \leftrightarrow 2 \mathrm{UF}_{3}(\mathrm{~m})+\mathrm{CrF}_{2}(\mathrm{~m})
$$

The $[\mathrm{U}(\mathrm{IV})] /[\mathrm{U}(\mathrm{III})]$ ratio was reduced down to 60 using beryllium metal. In total, three corrosion tests with same exposure time for fuel $71 \mathrm{LiF}-27 \mathrm{BeF}_{2}-2 \mathrm{UF}_{4}$ salt and Hastelloy-N (UNS 10003) alloy specimens at different $[\mathrm{U}(\mathrm{IV})] /[\mathrm{U}(\mathrm{III})]$ ratios 42,60 , and 85 were carried out.

\subsection{Selective chromium corrosion}

The metallographic structure of the reaction layer (at surface/under the surface) for the Hastelloy-N alloy specimens and its phase element composition were studied by scanning electron microscope (SEM). The test data for specimens after exposure in the fuel salt containing tellurium for $[\mathrm{U}(\mathrm{IV})] /[\mathrm{U}(\mathrm{III})]$ ratios 42 and 85 are presented in Figures 6 and 7. As can be seen from Figure 6, the surface reaction layer of the alloy exposed in fuel salt at the lower redox potential consists mainly of four phases. The element composition and average concentration of molybdenum and silicon contained in the alloy of each phase are quite different from it before exposure (as shown in Fig. 4).

The chromium on the specimen surface is oxidized by uranium tetrafluoride according to the reaction (4) and dissolved in the fuel salt. As a result, the chromium concentration on the specimen surface is depleted down to $3.5 \mathrm{wt} . \%$. The concentration of iron remained at the before exposure level. The silicon content increases on all surface, the concentration of silicon in each phase is correlated with the molybdenum and reach the maximum together with molybdenum.

Carbon was also found in the various phases with high molybdenum content. It seems that due to the high carbon content, the aggregation of the carbide phases of molybdenum, silicon and nickel occurs, which occurs more on the surface of the alloy than in the grains. The similar corrosion behavior of the Hastelloy-N alloy with accumulation of carbides on reaction surface was also found for a molten $\mathrm{LiF}-\mathrm{BeF}_{2}$ salt mixture exposed in graphite crucible [18-25].

After exposure in the fuel salt with $[\mathrm{U}(\mathrm{IV})] /[\mathrm{U}(\mathrm{III})]$ ratio 85 at $800^{\circ} \mathrm{C}$, there was no qualitative change in the surface layer. The content of molybdenum was still not uniform and the chromium decreased down to 1.7 wt. $\%$. Figure 7 shows scan data on the contents of the nickel, molybdenum, chromium, and iron in a grain range from the surface reaction layer of the alloy specimen to its depth. After exposure in the fuel salt with $[\mathrm{U}(\mathrm{IV})] /[\mathrm{U}(\mathrm{III})]$ ratio 85 , a significant depletion of chromium was observed for the specimen depth of $8 \mu \mathrm{m}$ (see Figs. 6d and 6e). The content of iron remained at its initial level.

The formation of secondary nickel-molybdenum carbide phases in the grain matrix (see Fig. 6) in the subsurface layer in the form of rounded particles with sizes up to $5 \mu \mathrm{m}$ and an increased molybdenum content leads to depletion of its content in the alloy grain around these particles. Moreover, the larger the particle, the lower the average concentration of molybdenum near it and the higher the radius of the layer depleted in molybdenum around the particle. This again confirms that the specified level of molybdenum in Hastelloy-N alloy (16-18wt.\%) in the presence of an increased carbon content leads to instability of the phase state in the alloy and the formation of secondary carbide phases. That is why, when ORNL developing Hastelloy-N modified [9], it was recommended to reduce content of the molybdenum in the alloy down to 10 $12 \mathrm{wt} . \%$ and minimize presence of silicon compared to the INOR-8.

Therefore, the corrosion of the Hastelloy-N alloy can be characterized by the selective diffusion of the chromium to the alloy surface, and its oxidation on the specimen surface with subsequent dissolution according to equation (4). The corrosion rate (based on the weight loss) at $800^{\circ} \mathrm{C}$ and $[\mathrm{U}(\mathrm{IV})] /[\mathrm{U}(\mathrm{III})]=85$ was more than twice higher compared to obtained at $760^{\circ} \mathrm{C}$ and $[\mathrm{U}(\mathrm{IV})] /[\mathrm{U}(\mathrm{III})]=42$. 
Table 4. Corrosion resistance of the Hastelloy- $\mathrm{N}$ alloy in the fuel $71 \mathrm{LiF}-27 \mathrm{BeF}_{2}-2 \mathrm{UF}_{4}$ salt (mole \%) containing tellurium metal vs. temperature $(T)$ and $[\mathrm{U}(\mathrm{IV})] /[\mathrm{U}(\mathrm{III})]$ ratio.

\begin{tabular}{llllll}
\hline$T^{\circ} \mathrm{C}$ & {$[\mathrm{U}(\mathrm{IV})] /[\mathrm{U}(\mathrm{III})]$} & $\begin{array}{l}\text { Exposure time } \\
\mathrm{h}\end{array}$ & $\begin{array}{l}\text { Corrosion rate } \\
\mu \mathrm{m} / \mathrm{yr}\end{array}$ & $\begin{array}{l}\text { Crack depth } \\
\mu \mathrm{m}\end{array}$ & $\begin{array}{l}K \\
\mathrm{ps} \cdot \mu \mathrm{m} / \mathrm{cm}\end{array}$ \\
\hline 760 & 42 & 256 & 21 & No IGC & \\
750 & 60 & 250 & $*$ & 69 & 3500 \\
800 & 85 & 248 & 45 & 148 & 4490 \\
\hline
\end{tabular}

\subsection{Tellurium intergranular cracking}

In corrosion test, tellurium was transferred from the source to the specimens' surface by fuel salt convection. Data shows the presence of $0.2-0.8 \mathrm{wt} . \%$ of tellurium in the reaction layer of specimen surface. The specimens tested at $[\mathrm{U}(\mathrm{IV})] /[\mathrm{U}(\mathrm{III})]$ ratios 42 and 85 showed that surface Te concentration is 0.6 and $0.3 \mathrm{wt} . \%$, respectively. Metallographic structure of the undersurface layer for the Hastelloy-N alloy after exposure in fuel $71.2 \mathrm{LiF}-$ $26.8 \mathrm{BeF}_{2}-\mathrm{UF}_{4}$ salt containing tellurium is shown in Figure 8. Micrographs of the specimens tested at $[\mathrm{U}(\mathrm{IV})] /[\mathrm{U}(\mathrm{III})]$ ratio 42 showed no traces of IGC.

It is seen from Figure 8 that along the grain boundaries in both tests, there are elongated solid chains of carbide particles. The scanning line microanalysis done along the entire length of the specimens tested in fuel salt with $[\mathrm{U}(\mathrm{IV})] /[\mathrm{U}(\mathrm{III})]$ ratio 42 has shown a uniform distribution of chromium and iron, and partly molybdenum. Molybdenum together with silicon form carbide particles elongated along the boundary between grains. The presence of any traces of tellurium on the grain boundaries in the sample exposed to salt with a low redox potential is not detected.

The tellurium concentration decreased from the surface to the depth in the specimen exposed to fuel salt with a higher redox potential. The peak concentration of tellurium was mainly found at the junction of the carbide particles and at the grain boundary surface. This is consistent with the conclusion made in [19-21]. It is pointed out in these papers that the tellurium will aggregate and form a chromium telluride at the junction of the carbide particles and the grain surface. This conclusion can be supported by the fact that the concentration distribution curve shows that there has a high chromium content in the aggregation of tellurium. It should be pointed out that the distribution curves of manganese and tellurium have the same shapes. The maximum concentration of manganese in the probes is consistent with the maximum concentration of tellurium. Note that in addition to chromium telluride, unstable manganese telluride may be formed with the diffusion of tellurium along the grain boundary.

Table 4 shows that there is a strong threshold correlation between corrosion rate of Hastelloy- $\mathrm{N}$ alloy (UNS No 10003) and [U(IV)]/[U (III)] ratio in the fuel salt.

For $[\mathrm{U}(\mathrm{IV})] /[\mathrm{U}(\mathrm{III})]$ ratio 42 and specimen temperature $760{ }^{\circ} \mathrm{C}$, the alloy is not the subject for IGC. At the same temperature and corrosion time, strong IGC of specimens for $[\mathrm{U}(\mathrm{IV})] /[\mathrm{U}(\mathrm{III})]$ ratio 60 was found. Increasing the
$[\mathrm{U}(\mathrm{IV})] /[\mathrm{U}(\mathrm{III})]$ ratio of fuel salts to $[\mathrm{U}(\mathrm{IV})] /[\mathrm{U}(\mathrm{III})]=85$ with increase of the temperature up to $780-800{ }^{\circ} \mathrm{C}$ will result in stronger IGC in the Hastelloy- $\mathrm{N}$ alloy: parameter $K=4490 \mathrm{ps} \cdot \mu \mathrm{m} / \mathrm{cm}$ and the crack depth $L_{\max }=148 \mu \mathrm{m}$.

\section{Conclusion}

It is pointed out that the tellurium IGC and the selective chromium corrosion of the Hastelloy- $\mathrm{N}$ alloy in fuel LiF$\mathrm{BeF}_{2}-\mathrm{UF}_{4}$ salt can be controlled by the $[\mathrm{U}(\mathrm{IV})] /[\mathrm{U}(\mathrm{III})]$ ratio. The chromium corrosion mechanism is caused by the oxidation of chromium on the alloy surface by reaction with uranium tetrafluoride, followed by its dissolution in the melt and depletion of the subsurface alloy layer on chromium by its diffusion from the depth of the specimen to the "structural metal-fuel salt" interface. The mechanism of tellurium IGC of Hastelloy-N alloy is caused by the diffusion of tellurium along the grain boundaries with the formation of unstable tellurides with both base metals and alloying additives. The tellurium IGC of Hastelloy-N alloy exposed in fuel $\mathrm{LiF}-\mathrm{BeF}_{2}-\mathrm{UF}_{4}$ salt can be avoided. The selective chromium corrosion can be minimized to acceptable level for the temperatures up to $760^{\circ} \mathrm{C}$ when [U(IV)]/ [U(III)] ratio is below $30-40$.

This work was supported by the National Research Center "Kurchatov Institute" (NRC-KI) and Shanghai Institute of Applied Physics (SINAP), Chinese Academy of Sciences.

\section{Author contribution statement}

Aleksandr Surenkov is a senior researcher at NRC-KI with specialization in materials compatibility with molten salts. $\mathrm{He}$ is in charge of the experimental corrosion studies involving fuel and coolant salts. He participated in the development and operation of a corrosion loop, preparation of high-nickel alloys specimens and fuel salt for corrosion tests and, material exposure in the fuel salt, analysis of experimental results. Victor Ignatiev is a professor and scientific leader of the MSR Project at NRC-KI. He participated in the development of the program for material studies with fuel salt in corrosion loop as well as analysis and generalization of the experimental results and preparing the manuscript for publication. Mikhail Presnyakov is a researcher at NRC-KI with specialization in electron-microscopic studies. He is in charge of the alloy nano-samples preparation for electron microscopic studies. He conducted microanalysis of the structure and 
composition of alloy samples after corrosion tests using an electron microscope. Jianqiang Wang is a professor at SINAP. He is in charge of the academic exchange between NRC-KI and SINAP. He participated in the revision of this manuscript. Zhijun $\mathrm{Li}$ is a professor at SINAP. He participated in the studies and academic exchange on the corrosion of metallic materials induced by Te in molten fluoride salt. Xinmei Yang is researcher at SINAP. She participated in the revision of this manuscript and academic exchange on the corrosion of metallic materials in molten fluoride salts. She is in charge of the development and operation of corrosion loops at SINAP. Zhimin Dai, director at SINAP. He promoted the development of international cooperation between NRC-KI and SINAP.

\section{References}

1. V. Ignatiev, O. Feynberg, A. Surenkov et al., Molten-salt reactors: new possibilities, problems and solutions, At. Energy 112, 135 (1970)

2. P.N. Haubenreich, J.R. Engel, Experience with the MoltenSalt Reactor experiment, Nucl. Appl. Technol. 8, 118 (1970)

3. V. Novikov, V. Ignatiev, V. Fedulov, V. Cherednikov, Molten salt reactors: perspectives and problems (Energoatomizdat, Moscow, 1990)

4. V. Ignatiev, V. Novikov, A. Surenkov, V. Fedulov, The state of the problem on materials as applied to molten-salt reactor: problems and ways of solution. Preprint IAE-5678/11 (Institute of Atomic Energy, Moscow, 1993)

5. V. Ignatiev, V. Novikov, A. Surenkov, Testing loops with salt melts (out-of-core and in-core experimental studies), Preprint IAE-5307/4 (Institute of Atomic Energy, Moscow, 1991)

6. MSR Program Semiannual Progress Report, ORNL-5132, Oak Ridge, TN, USA, 1976

7. MSR Program Semiannual Progress Report, ORNL-5078, Oak Ridge, TN, USA, 1975

8. J.R. Keiser, Status of Tellurium Hastelloy-N Studies in Molten Fluoride Salts, ORNL-TM-6002, Oak Ridge, TN, USA, 1977

9. H.E. McCoy, Status of Materials Development for Molten Salt Reactors, ORNL-TM-5920, Oak Ridge, TN, USA, 1978

10. V. Ignatiev, A. Surenkov, Alloys compatibility in molten salt fluorides: Kurchatov Institute related experience, J. Nucl. Mater. 441, 583 (2013)

11. V. Ignatiev, A. Surenkov, I. Gnidoi, V. Uglov, S. Konakov, Experimental study on tellurium corrosion of nickelmolybdenum alloys with ternary molten salt fluorides of lithium, beryllium and uranium, At. Energy 120, 326 (2016)
12. A.I. Surenkov, V. Ignatiev, S. Abalin, S. Konakov, V. Uglov, Corrosion resistance and mechanical stability of nickel alloys in molten-salt nuclear reactors, At. Energy 124, 34 (2018)

13. V. Ignatiev, A. Surenkov, Corrosion phenomena induced by molten salts in generation IV nuclear reactors, in Structural Materials for Generation IV Nuclear Reactors, edited by P. Ivon, Woodhead publishing series in energy, 106 (Elsevier, Amsterdam, 2016), Chap. 5, pp. 153-191

14. V. Afonichkin, A. Bovet, V. Shishkin, Salts purification and voltammetric study of electroreduction of U(IV) to U(III) in $\mathrm{LiF}-\mathrm{ThF}_{4}$ melt, J. Nucl. Mater. 419, 347 (2011)

15. V. Afonichkin, A. Bovet, V. Ignatiev et al., Dynamic reference electrode for investigation of fluoride melts containing beryllium difluoride, J. Fluorine Chem. 130, 83 (2009)

16. H.W. Jenkins, G. Mamantov, D.L. Manning, J.P. Young, EMF and voltammetric measurements on the $\mathrm{U}(\mathrm{IV}) / \mathrm{U}(\mathrm{III})$ couple in molten LiF-BeF ${ }_{2}-\mathrm{ZrF}_{4}$, J. Electrochem. Soc. 116, 1712 (1969)

17. M. Straka, M. Korenko, F. Lisy, Electrochemistry of uranium in $\mathrm{LiF}-\mathrm{BeF}_{2}$ melt, J. Radioanal. Nucl. Chem. 284, 245 (2010)

18. X.-X. Yea, H. Aia, Z. Guo, H. Huang, L. Jiang, J. Wang, Z. Li, X. Zhou, The high-temperature corrosion of Hastelloy N alloy (UNS N10003) in molten fluoride salts analyzed by STXM, XAS, XRD, SEM, EPMA, TEM/EDS, Corros. Sci. 106, 249 (2016)

19. L. Lu, Y. Jia, X.-X. Ye, M. Luo, F. Song, Z. Li, Z. Jiang, Local structure study of tellurium corrosion of nickel alloy by X-ray absorption spectroscopy, Corros. Sci. 108, 169 (2016)

20. H. Cheng, B. Leng, K. Chen, Y. Jia, J. Dong, Z. Li, X. Zhou, EPMA and TEM characterization of intergranular tellurium corrosion of Ni-16Mo-7Cr-4Fe super alloy, Corros. Sci. 97, 1 (2015)

21. J. Li, S.L. Shrestha, Y. Long, Z. Li, Z. Xintai, The formation of eutectic phases and hot cracks in one Ni-Mo-Cr super alloy, Mater. Des. 93, 324 (2016)

22. K. Yu, Z. Jiang, Z. Li, Effects of post-weld heat treatment on microstructure and mechanical properties of laser welds in GH3535 super alloy, Opt. Laser Technol. 81, 18 (2016)

23. Z. Xu, L. Jiang, J. Dong, Z. Li, X. Zhou, The effect of silicon on precipitation and decomposition behaviors of $\mathrm{M}_{6} \mathrm{C}$ carbide in a Ni-Mo-Cr super alloy, J. Alloys Compd. 620, 197 (2015)

24. H. Cheng, F. Han, Y. Jia, Z. Li, X. Zhou, Effects of Te on intergranular embrittlement of a Ni-16Mo-7Cr alloy, J. Nucl. Mater. 461, 122 (2015)

25. J. Li, S.L. Shrestha, Y. Long, Z. Li, Z. Xintai, Investigation on corrosion behavior of Ni-based alloys in molten fluoride salt using synchrotron radiation techniques, J. Nucl. Mater. 440, 124 (2013)

Cite this article as: Aleksandr Surenkov, Victor Ignatiev, Mikhail Presnyakov, Jianqiang Wang, Zhijun Li, Xinmei Yang, Zhimin Dai, Effect of the $[\mathrm{U}(\mathrm{IV})] /[\mathrm{U}(\mathrm{III})]$ ratio on selective chromium corrosion and tellurium intergranular cracking of Hastelloy $\mathrm{N}$ alloy in the fuel $\mathrm{LiF}-\mathrm{BeF}_{2}-\mathrm{UF}_{4}$ salt, EPJ Nuclear Sci. Technol. 6, 4 (2020) 